\title{
Development of systemic bacteraemia after oral inoculation of vancomycin-resistant enterococci in mice
}

\author{
SHUICHI MIYAZAKI, TOSHIHIKO FUJIKAWA, INTETSU KOBAYASHI, TETSUYA MATSUMOTO, \\ KAZUHIRO TATEDA and KEIZO YAMAGUCHI
}

Department of Microbiology, Toho University School of Medicine, Tokyo, Japan

\begin{abstract}
Bacteraemia caused by vancomycin-resistant enterococci (VRE) is an important clinical problem because there are only a few potent antimicrobial agents against such bacteria. Therefore, understanding the pathogenic mechanisms of VRE bacteraemia is important for prophylaxis. This study shows that treatment of mice with cyclophosphamide and a combination of metronidazole, kanamycin and vancomycin reduced normal intestinal flora and induced systemic VRE bacteraemia. Translocation of VRE and the normal intestinal flora to the mesenteric lymph nodes, liver, spleen and blood, and mortality rate were dependent on treatment with cyclophosphamide and each of the three antimicrobial drugs. Among the different strains studied, C57BL/6 mice were the most susceptible to VRE. The virulence of vancomycin-resistant Enterococcus faecalis was greater than that of vancomycin-resistant Ent. faecium. On the day after inoculation of VRE, Escherichia coli was also detected in many VRE-positive specimens including blood, liver and the mesenteric lymph nodes. Moreover, both VRE and $E$. coli were detected simultaneously in almost all blood samples obtained from dead and dying mice, and VRE organisms outnumbered $E$. coli in those samples by 100:1 or more. These results indicate that changes in normal intestinal flora by administration of antimicrobial drugs and severity of neutropenia induced by cyclophosphamide are important factors that contribute to the development of systemic VRE bacteraemia. $E$. coli may be intimately associated with the establishment of VRE translocation.
\end{abstract}

\section{Introduction}

Enterococci are normal inhabitants of the intestinal tract of man and animals, and 16 or more species of enterococci are currently recognised. Of these, two species, Enterococcus faecalis and Ent. faecium, are the most important causes of enterococcal infections in man. About $80-90 \%$ of enterococcal infections in man are caused by Ent. faecalis and $5-15 \%$ are caused by Ent. faecium [1,2]. Singh et al. [3] indicated that the emergence of multidrug-resistant enterococci during the past decade has converted some enterococci from being difficult to treat to being impossible to treat. Enterococcal endocarditis has long been recognised as a therapeutic challenge, compared with endocarditis caused by other streptococci, and since vancomycin became the agent of 'last resort' for the treatment of

Received 27 Sept. 2000; revised version accepted 2 Feb. 2001.

Corresponding author: Dr S. Miyazaki (e-mail: shuichi@, med.toho-u.ac.jp). infections caused by multidrug-resistant, highly penicillin-resistant Ent. faecium, it was of great concern that the first reports of vancomycin-resistant enterococci in Europe began to appear in mid-1980s [4, 5]. Of nearly 11000 enterococcal isolates examined in 1989 in the USA, $0.3 \%$ were resistant to vancomycin but $7.9 \%$ of isolates in 1993 were resistant, a 20-fold increase over the 4-year period [6]. Thus, vancomycinresistant enterococci (VRE) are now the cause of serious problems in Europe and the USA [7, 8].

Two mechanisms might have played a role in the increased frequency of VRE: enterococci are part of normal gut flora, and the emergence of vancomycin resistance was associated with increased use of oral vancomycin for the treatment of documented and presumed Clostridium difficile infection [9-11]. Of note, resistance to vancomycin emerged in a strain highly resistant to ampicillin [12]. In a study reported by Jochimsen and co-workers [13], the main sites of infection were the bloodstream (31\%), urinary tract $(46 \%)$ and wounds $(15 \%)$, while the main sites of 
positive culture for colonised case-patients included the urinary tract $(31 \%)$, wounds $(9 \%)$ and stool or rectal swab (58\%).

While the pathogenicity of the enterococci is solidly confirmed in cases of meningitis and endocarditis, it has been difficult to establish their role in bloodstream infections, because enterococci do not produce potent exotoxins [14].

Wells et al. [15, 16] described a murine model of enterococcal translocation across an intact intestinal epithelium in mice orally inoculated with Ent. faecalis and treated with broad-spectrum antibiotics. In their studies, $13 \%$ of infected mice died within 3 weeks but it was not clear whether death was due to overwhelming enterococcal infection or dissemination of other intestinal pathogens. The mechanisms of bacteraemia in enterococcal infections have not yet been established. Of particular interest is the fact that enterococci are part of the normal gut flora and do not possess any strong virulence factor. A study into possible mechanisms of enterococcal bacteraemia was initiated in order to understand the mechanism of entry of these problematic organisms into the bloodstream and identify factors associated with the development of enterococcal bacteraemia following oral inoculation of VRE organisms in mice.

\section{Materials and methods}

\section{Organisms}

Ent. faecalis V583 and Tx2486 were gifts from Dr B.E. Murray (University of Texas, Houston, TX, USA). The former strain has been described previously [17]. Ent. faecalis TMS2 and TMS5 were isolated from urine samples of Japanese patients. Ent. faecium TMS4 and TMS5 have been described previously [18].

\section{Animals and treatment}

CBA, C57BL/6, BALB/c, BALB/CNU, C3H, ICR, ICRNU/NU, BDF1, CDF1, DBA/2, DBA/1J, B6C3F1 and SCID strains of 5-week-old mice were a gift from Charles River Japan (Atsugi, Kanagawa, Japan). Mice were pretreated intraperitoneally with cyclophosphamide (Shionogi, Osaka, Japan) $250 \mathrm{mg} / \mathrm{kg}, 3$ days before oral inoculation of VRE organisms. To reduce normal intestinal flora, a combination of metronidazole, kanamycin and vancomycin was administered orally once a day for 3 days, each at a dose of $100 \mathrm{mg} / \mathrm{kg}$ commencing on the same day as administration of cyclophosphamide, unless otherwise indicated. After treatment with antimicrobial agents and cyclophosphamide, mice were inoculated orally with $c .1 \times 10^{9} \mathrm{VRE}$ organisms from overnight cultures on blood agar plates. Mortality was assessed daily for 7 days after oral inoculation. Heart blood samples of deceased mice were obtained for detection of the pathogenic micro-organ- isms. A portion of the sample $(0.1 \mathrm{ml})$ was spread on a blood agar plate and incubated at $35^{\circ} \mathrm{C}$ for $24 \mathrm{~h}$. All experiments were performed twice to confirm reproducibility. The experimental protocol was approved by the Ethics Review Committee for Animal Experimentation of Toho University School of Medicine.

\section{Enumeration of viable bacteria in colon, mesenteric lymph nodes, spleen, liver and blood samples}

Blood samples were obtained by heart puncture with a disposable heparinised syringe under ketamine-xylazine anaesthesia. The spleen, liver and mesenteric lymph nodes (MLN) were dissected out at the time of blood sampling but before the excision of the colon. Each organ was homogenised and diluted in pre-reduced Hanks's Balanced Salts Solution (Gibco Laboratories, Grand Island, NY, USA) supplemented with cysteine $\mathrm{HCl}$ (Sigma) $0.05 \%$ (HBSSs). In the next step, the colon was dissected out aseptically, immediately transferred to an anaerobic chamber (Forma Scientific, Marietta, OH, USA) and its contents were weighed, then suspended in HBSSs. The homogenate was serially diluted with the same solution and plated on to various plates: Sheep Blood Agar (Eiken, Tokyo, Japan) for total aerobes, EF Agar (Nissui, Tokyo, Japan) for enterococci, Enterococcosel Agar with vancomycin (BBL, MO, USA) for VRE, CPS-ID2 (bioMérieux, Paris, France) for Escherichia coli, GAM Agar (Nissui) for total anaerobes, BL Agar (Eiken) for Bacteroides spp. and LBS Agar (BBL) for Lactobacillus spp. Bacterial isolates were identified by standard methods and Vitek ID kits (bioMerieux).

\section{Statistical analysis}

Differences between groups in viable bacterial counts were examined for statistical significance by the MannWhitney U test.

\section{Results}

\section{Changes in normal intestinal flora}

The influence of the combinations of antimicrobial drugs on the normal intestinal flora was assessed first. For this purpose, mice ( $n=5 /$ group) were pretreated with the antimicrobial drugs alone or in combination. Intraperitoneal administration of cyclophosphamide did not change the number or type of normal intestinal flora (data not shown). On the other hand, pretreatment with kanamycin reduced the colonic content of Enterobacteriaceae (mainly E. coli) by $1 \log _{10} \mathrm{cfu} / \mathrm{g}$ and Lactobacillus spp. by $4 \log _{10} \mathrm{cfu} / \mathrm{g}$ (Table 1 ). Administration of metronidazole reduced the number of total anaerobes and Bacteroides spp, by c. $2 \log _{10} \mathrm{cfu} / \mathrm{g}$, but increased the number of Enterobacteriaceae (mainly E. coli) to $10^{8} \mathrm{cfu} / \mathrm{g}$ and that of Enterococcus spp. to $10^{6} \mathrm{cfu} / \mathrm{g}$. Simultaneous administration of 
Table 1. Effects of drug administration on the normal intestinal flora

\begin{tabular}{|c|c|c|c|c|c|}
\hline \multirow[b]{2}{*}{ Bacterial flora } & \multicolumn{5}{|c|}{ Mean (SD) viable counts in colon $\left(\log _{10} \mathrm{cfu} / \mathrm{g}\right.$ of content) in mice given } \\
\hline & Control & Kanamycin & Metronidazole & $\begin{array}{l}\text { Kanamycin }+ \\
\text { metronidazole }\end{array}$ & $\begin{array}{c}\text { Kanamycin }+ \\
\text { metronidazole }+ \\
\text { vancomycin }\end{array}$ \\
\hline Total aerobes & $5.6(0.2)$ & $6.5(1.2)$ & $8.2(0.2)^{*}$ & $7.2(0.4)^{*}$ & $6.1(1.2)$ \\
\hline Enterobacteriaceae & $5.4(0.3)$ & $4.1(0.3)^{*}$ & $8.1(1.2)^{*}$ & $6.5(0.5)^{*}$ & $1.8(2.3)^{*}$ \\
\hline E. coli & $5.3(0.2)$ & $4.0(0.4)^{*}$ & $8.1(0.1)^{*}$ & ND & $1.8(2.3)^{*}$ \\
\hline Enterococcus spp. & $5.1(0.3)$ & $5.1(3.3)$ & $6.0(0.4)^{\dagger}$ & $4.8(0.2)$ & $1.8(2.3)^{*}$ \\
\hline Total anaerobes & $9.0(1.1)$ & $9.6(1.2)$ & $8.1(0.1)^{\dagger}$ & $6.1(2.5)^{*}$ & $5.2(1.0)^{*}$ \\
\hline Bacteroides spp. & $8.4(1.6)$ & $9.6(1.2)$ & $7.0(0.1)^{\dagger}$ & $6.0(2.1)^{*}$ & ND \\
\hline Lactobacillus spp. & $7.7(0.1)$ & $3.2(2.2)^{*}$ & $7.4(0.2)$ & $3.4(2.4)^{*}$ & $3.6(0.8)^{*}$ \\
\hline Clostridium spp. & ND & ND & ND & ND & ND \\
\hline
\end{tabular}

$*_{\mathrm{p}}<0.01$ compared with control.

${ }^{\dagger} \mathrm{p}<0.05$ compared with control.

kanamycin and metronidazole markedly reduced the numbers of viable $E$. coli to below the detection limit and the total anaerobes, Bacteroides spp. and Lactobacilli spp. to $1-0.01 \%$, compared with control mice. In mice pretreated with all three antimicrobial agents, the bacterial counts of Enterobacteriaceae, E. coli, Enterococcus spp., total anaerobes, Bacteroides spp. and Lactobacillus spp. diminished significantly to $<0.1 \%$, relative to control mice.

\section{Translocation of normal intestinal organisms by treatment with antimicrobial agents and cyclophosphamide}

Bacterial counts in blood, liver, spleen and MLN tissues were below detection limits in control and cyclophosphamide-treated mice $(n=5 /$ group, Table 2 ). However, in two of five mice treated with all three antimicrobial agents, both $E$. coli and enterococci or $E$. coli alone were detected in MLN, but not in other tissues. In mice treated with cyclophosphamide and all three antimicrobial agents, E. coli was detected in all MLN samples as well as in $20 \%$ of spleen samples (one of five), while E. coli alone was detected in $80 \%$ of liver samples (four of five), but no organisms were detected in any of the blood samples. The viable counts of $E$. coli detected in various tissues were 10-200 cfu/tissue.
Based on these results and for the purpose of establishing VRE bacteraemia in mice, kanamycin, metronidazole and vancomycin were administered orally together with intraperitoneal injection of cyclophosphamide.

Effects of kanamycin, metronidazole, vancomycin and cyclophosphamide on mortality rate due to oral administration of VRE

Administration of oral kanamycin, metronidazole or vancomycin alone did not influence mortality rate in infected mice $(\mathrm{n}=10)$ pretreated with cyclophosphamide. On the other hand, the mortality rate of mice $(\mathrm{n}=10)$ pretreated with cyclophosphamide and with two antimicrobial agents was $10 \%$ and mortality increased further to $30 \%$ when the three antimicrobial agents were used simultaneously. In repeat experiments with 30 animals under treatment with cyclophosphamide and the three antimicrobial drugs, the mortality rate of $30 \%$ was confirmed. The effect of pretreatment with cyclophosphamide on mortality rate was also examined. There were no deaths in mice $(n=10)$ not treated with cyclophosphamide but treated with kanamycin, metronidazole and vancomycin at doses of $100 \mathrm{mg} / \mathrm{kg} /$ day for 3 days.

Table 2. Effects of drug administration on translocation of normal intestinal flora

\begin{tabular}{|c|c|c|c|c|c|}
\hline \multirow{2}{*}{$\begin{array}{l}\text { Groups } \\
\text { of mice }\end{array}$} & \multirow{2}{*}{$\begin{array}{c}\text { Number } \\
\text { positive/ } \\
\text { number } \\
\text { tested }\end{array}$} & \multicolumn{4}{|c|}{ Identity of translocating species (cfu/tissue sample) in } \\
\hline & & Blood & Liver & Spleen & MLN \\
\hline Normal & $0 / 5$ & NG & NG & NG & NG \\
\hline CY-treated & $0 / 5$ & NG & NG & NG & NG \\
\hline \multirow[t]{2}{*}{ Drug-treated } & $2 / 5$ & NG & NG & NG & $\begin{array}{l}\text { E. coli }(80) \\
\text { Enterococci }(60)\end{array}$ \\
\hline & & NG & NG & NG & E. coli $(30)$ \\
\hline \multirow[t]{5}{*}{ Drug- and CY-treated } & $5 / 5$ & NG & E. coli $(10)$ & NG & E. coli $(10)$ \\
\hline & & NG & E. coli $(200)$ & NG & E. coli $(10)$ \\
\hline & & NG & E. coli $(200)$ & NG & E. $\operatorname{coli}(30)$ \\
\hline & & NG & NG & E. coli $(160)$ & E. coli $(80)$ \\
\hline & & NG & E. coli $(10)$ & NG & E. coli $(10)$ \\
\hline
\end{tabular}

CY, cyclophosphamide; NG, no growth; MLN, mesenteric lymph nodes. 


\section{Comparison of virulence between species}

Oral inoculation of vancomycin-resistant Ent. faecalis VS83 organisms in mice $(\mathrm{n}=10)$ pretreated with cyclophosphamide and three antimicrobial agents resulted in $30 \%$ mortality rate with the majority of deaths occurring 2 days after inoculation (range 1-4 days) and was $20 \%$ in those inoculated with other vancomycin-resistant Ent. faecalis Tx2386, TMS2 or TMS5. In comparison, the mortality rate was $10 \%$ in mice $(\mathrm{n}=10)$ inoculated with vancomycin-resistant Ent. faecium.

\section{Comparison of virulence between mouse strains}

Differences in mortality rates in different strains of mice were assessed. For this purpose, each strain of mice $(\mathrm{n}=10$ each) pretreated with cyclophosphamide and three antimicrobial agents was inoculated orally with Ent. faecalis V583. The mortality rate in C57BL/ 6, DBA $/ 2$ and $\mathrm{B} 6 \mathrm{C} 3 \mathrm{~F} 1$ strains was $30 \%, 20 \%$ and $10 \%$, respectively, and death was observed 1-3 days after oral inoculation of the organisms. There were no deaths in other $\mathrm{CBA}, \mathrm{BALB} / \mathrm{c}, \mathrm{BALB} / \mathrm{CNU}, \mathrm{C} 3 \mathrm{H}$, ICR, ICRNU/NU, BDF1, CDF1, DBA/1J and SCID strains of mice. Based on the above results, Ent. faecalis V583 was used as the infecting organism and C57BL/6 strain mice as the experimental animal in the remaining experiments.

Translocation of VRE in cyclophosphamide- and drug-treated mice

On the day after oral inoculation of VRE, normal mice and mice pretreated with cyclophosphamide or all three antimicrobial drugs, or both (10 animals/group) were killed to determine the extent of VRE translocation. In the case of oral administration of VRE in normal mice, VRE were detected in $50 \%$ of MLN samples at $10-470 \mathrm{cfu} /$ tissue sample (Table 3). Furthermore, VRE alone and both VRE and E. coli were detected in each blood sample of those VRE-positive samples. Micro-organisms were not detected in any liver and spleen samples. In the case of neutropenic mice, only $10 \mathrm{cfu}$ of VRE/tissue sample were detected in two MLN samples, and VRE and staphylococci were detected in each liver sample (Table 4). On the other hand, VRE were detected in $60 \%$ of blood samples, and E. coli was simultaneously present in $c .70 \%$ of these samples. In contrast, in the case of mice treated with three

Table 3. Translocation of intestinal bacteria into the MLN, liver, spleen and blood of normal mice

\begin{tabular}{lllll}
\hline & \multicolumn{4}{c}{ Identity of translocating species (cfu/tissue sample) in } \\
\cline { 2 - 5 } Mouse no. & Blood & Liver & Spleen & MLN \\
\hline 1 & NG & NG & NG & NG \\
2 & VRE (30) & NG & NG & VRE (10) \\
& E. coli (20) & $\ldots$ & $\ldots$ & $\ldots$ \\
3 & NG & NG & NG & NG \\
4 & NG & NG & NG & VRE (470) \\
5 & NG & NG & NG & NG \\
6 & VRE (10) & NG & NG & VRE (10) \\
7 & NG & NG & NG & NG \\
8 & NG & NG & NG & NG \\
9 & NG & NG & NG & VRE (40) \\
10 & NG & NG & NG & VRE (90) \\
\hline
\end{tabular}

NG, no growth; MLN, mesenteric lymph nodes.

Table 4. Translocation of intestinal bacteria into the MLN, liver, spleen and blood of neutropenic mice without administration of antimicrobial drugs

\begin{tabular}{|c|c|c|c|c|}
\hline \multirow[b]{2}{*}{ Mouse no. } & \multicolumn{4}{|c|}{ Identity of translocating species (cfu/tissue sample) in } \\
\hline & Blood & Liver & Spleen & MLN \\
\hline \multirow[t]{2}{*}{1} & VRE (10) & NG & NG & NG \\
\hline & E. coli $(10)$ & $\ldots$ & $\ldots$ & $\ldots$ \\
\hline \multirow[t]{2}{*}{2} & VRE (200) & NG & NG & NG \\
\hline & E. coli $(20)$ & $\ldots$ & $\ldots$ & $\ldots$ \\
\hline 3 & NG & Staphylococci (300) & NG & NG \\
\hline 4 & $\mathrm{NG}$ & $\mathrm{NG}$ & NG & NG \\
\hline \multirow[t]{2}{*}{5} & VRE (200) & NG & NG & NG \\
\hline & E. coli $(70)$ & $\ldots$ & $\ldots$ & $\ldots$ \\
\hline 6 & VRE (270) & $\mathrm{NG}$ & NG & VRE (10) \\
\hline 7 & VRE (50) & $\mathrm{NG}$ & NG & $\mathrm{NG}$ \\
\hline 8 & $\mathrm{NG}$ & NG & NG & VRE (10) \\
\hline \multirow[t]{2}{*}{9} & VRE (80) & VRE (30) & NG & $\mathrm{NG}$ \\
\hline & E. coli $(130)$ & $\ldots$ & $\ldots$ & $\ldots$ \\
\hline 10 & NG & NG & NG & NG \\
\hline
\end{tabular}

NG, no growth; MLN, mesenteric lymph nodes. 
antimicrobial drugs, VRE alone and both VRE and $E$. coli were detected in MLN samples of each of four mice (Table 5). VRE were detected in liver and spleen samples of five and four mice, respectively, and E. coli was simultaneously detected in $60 \%$ of liver samples and $25 \%$ of spleen samples. VRE alone and both VRE and $E$. coli were detected in blood samples of two and one mouse, respectively. In the case of neutropenic mice treated with three antimicrobial drugs, VRE were detected in $90 \%$ of MLN samples at 10-3000 cfu/tissue sample (Table 6). Furthermore, E. coli or staphylococci were simultaneously detected in $50 \%$ of these samples. VRE alone, both VRE and E. coli or staphylococci and $E$. coli alone were detected in liver samples of three, three, one and one mouse, respectively. VRE alone, both VRE and E. coli or staphylococci and E. coli alone were detected in spleen samples of one, two, one and three mice, respectively. Both VRE and E. coli were detected in three blood samples, and bacterial counts of VRE and E. coli were $10-1000 \mathrm{cfu} / \mathrm{ml}$ and $10-80 \mathrm{cfu} / \mathrm{ml}$, respectively. VRE alone were detected in two blood samples. In mice harbouring VRE at
$1000 \mathrm{cfu} / \mathrm{ml}$, VRE and E. coli were also detected in the liver, spleen and MLN.

When 24 mice were examined under the same conditions except for oral administration of the three antimicrobial agents at a higher dose (each $200 \mathrm{mg} /$ $\mathrm{kg}$ ), the mortality rate increased to $46 \%$ and death was observed 1-4 days after oral inoculation of the organisms. The viable counts of intestinal flora were assayed to determine the type of bacteria responsible for this high mortality (Table 7). At day 3 before the final dose of the agents, $3.9 \log _{10}$ cfu of VRE/g were detected, and the causative bacteria was identified as vancomycin-resistant Ent. gallinarum. On day 1 after the final dose of antimicrobial agents, the viable counts of all tested microbes were below the detection limits except for total aerobes (average $2.1 \log _{10} \mathrm{cfu} / \mathrm{g}$ ). Viable counts in the intestinal flora recovered to almost basal levels at day 28 after inoculation of organisms. However, viable counts of inoculated vancomycinresistant Ent. faecalis were still $8.1 \log _{10} \mathrm{cfu} / \mathrm{g}$ at day 28 after inoculation.

Table 5. Translocation of intestinal bacteria into the MLN, liver, spleen and blood of normal mice treated with antimicrobial drugs

\begin{tabular}{|c|c|c|c|c|}
\hline \multirow[b]{2}{*}{ Mouse no. } & \multicolumn{4}{|c|}{ Identity of translocating species (cfu/tissue sample) in } \\
\hline & Blood & Liver & Spleen & MLN \\
\hline \multirow[t]{2}{*}{1} & VRE (30) & VRE (310) & VRE (220) & VRE (600) \\
\hline & $\ldots$ & E. coli $(90)$ & E. coli $(40)$ & E. coli $(410)$ \\
\hline \multirow[t]{2}{*}{2} & E. $\operatorname{coli}(370)$ & E. coli $(520)$ & $\mathrm{NG}$ & E. $\operatorname{coli}(50)$ \\
\hline & VRE (100) & VRE $(250)$ & $\ldots$ & VRE (710) \\
\hline \multirow[t]{2}{*}{3} & $\mathrm{NG}$ & VRE (2500) & NG & VRE (270) \\
\hline & $\ldots$ & E. coli $(160)$ & $\ldots$ & E. coli $(10)$ \\
\hline 4 & NG & VRE $(30)$ & NG & $\mathrm{NG}$ \\
\hline 5 & $\mathrm{NG}$ & NG & VRE (10) & $\mathrm{NG}$ \\
\hline 6 & NG & $\mathrm{NG}$ & NG & VRE (10) \\
\hline 7 & NG & $\mathrm{NG}$ & NG & VRE (20) \\
\hline \multirow[t]{2}{*}{8} & NG & VRE (40) & VRE (150) & VRE (200) \\
\hline & $\ldots$ & $\ldots$ & $\ldots$ & E. coli $(420)$ \\
\hline 9 & VRE (10) & $\mathrm{NG}$ & $\mathrm{NG}$ & VRE $(80)$ \\
\hline 10 & NG & NG & VRE (20) & VRE (20) \\
\hline
\end{tabular}

$\mathrm{N}$, no growth; MLN, mesenteric lymph nodes.

Table 6. Translocation of intestinal bacteria into the MLN, liver, spleen and blood of neutropenic mice treated with antimicrobial drugs

\begin{tabular}{|c|c|c|c|c|}
\hline \multirow{2}{*}{$\begin{array}{l}\text { Mouse } \\
\text { no. }\end{array}$} & \multicolumn{4}{|c|}{ Identity of translocating species (cfu/tissue sample) in } \\
\hline & Blood & Liver & Spleen & MLN \\
\hline 1 & NG & NG & NG & VRE (20) \\
\hline 2 & NG & NG & NG & NG \\
\hline \multirow[t]{2}{*}{3} & VRE (10) & VRE (20) & VRE (200) & VRE (100) \\
\hline & E. $\operatorname{coli}(10)$ & E. coli $(10)$ & E. coli $(100)$ & E. coli $(30)$ \\
\hline 4 & NG & E. coli $(180)$ & E. $\operatorname{coli}(20)$ & E. coli $(30)$ \\
\hline \multirow[t]{2}{*}{5} & VRE (400) & VRE (70) & VRE (30) & VRE $(3000)$ \\
\hline & $\ldots$ & Staphylococci (300) & Staphylococci (150) & Staphylococci (3000) \\
\hline \multirow[t]{2}{*}{6} & VRE (500) & VRE (10) & $\ldots$ & VRE $(3000)$ \\
\hline & E. coli $(80)$ & $\ldots$ & E. coli $(20)$ & E. coli $(2000)$ \\
\hline \multirow[t]{2}{*}{7} & VRE (1000) & VRE (200) & VRE (250) & VRE (70) \\
\hline & $\ldots$ & E. coli $(100)$ & E. coli $(100)$ & E. coli $(250)$ \\
\hline 8 & NG & VRE (50) & $\mathrm{NG}$ & VRE (10) \\
\hline \multirow[t]{2}{*}{9} & VRE (10) & VRE (5000) & $\ldots$ & VRE (80) \\
\hline & E. coli $(20)$ & E. coli $(500)$ & E. coli $(20)$ & E. coli $(10)$ \\
\hline 10 & VRE (50) & VRE (130) & VRE (20) & VRE (20) \\
\hline
\end{tabular}

NG, no growth; MLN, mesenteric lymph nodes. 
Table 7. Characterisation of colonic bacteria after administration of metronidazole, kanamycin and vancomycin, each at $200 \mathrm{mg} / \mathrm{kg}$

\begin{tabular}{lccccc}
\hline & \multicolumn{5}{c}{ Mean (SEM) viable counts in colon $\left(\log _{10}\right.$ cfu/g of content) on $^{\dagger}$} \\
\cline { 2 - 7 } Bacterial flora & -3 & 1 & 3 & 14 & 28 \\
\hline Total aerobes & $5.9(0.5)$ & $2.1(1.1)^{*}$ & $7.0(1.0)^{*}$ & $9.4(0.3)^{*}$ & $7.1(1.2)^{*}$ \\
Enterobacteriaceae & $5.1(0.4)$ & $\mathrm{ND}$ & $4.7(3.2)$ & $7.0(1.2)^{*}$ & $5.8(1.3)$ \\
E. coli & $4.7(0.7$ & $\mathrm{ND}$ & $4.7(3.2)$ & $7.0(1.2)^{*}$ & $5.8(1.3)$ \\
Enterococcus spp. & $4.9(0.5)$ & $\mathrm{ND}$ & $6.8(0.9)^{*}$ & $9.3(0.3)^{*}$ & $8.1(2.1)^{*}$ \\
VRE & $3.9(1.5)$ & $\mathrm{ND}$ & $6.8(0.9)^{*}$ & $9.2(0.5)^{*}$ & $8.1(2.1)^{*}$ \\
Total anaerobes & $8.1(0.6)$ & $\mathrm{ND}$ & $4.3(2.9)^{*}$ & $2.4(2.6)^{*}$ & $7.2(1.0)$ \\
Bacteroides spp. & $8.1(0.7)$ & $\mathrm{ND}$ & $4.3(2.9)^{*}$ & $2.4(2.6)^{*}$ & $6.9(1.6)$ \\
Lactobacillus spp. & $6.6(0.7)$ & $\mathrm{ND}$ & $\mathrm{ND}$ & $\mathrm{ND}$ & $5.6(0.8)$ \\
Clostridium spp. & $\mathrm{ND}$ & $\mathrm{ND}$ & $\mathrm{ND}$ & $\mathrm{ND}$ & $\mathrm{ND}$ \\
* Days numbered in relation to time of final administration of antimicrobial drugs. \\
${ }^{\dagger}$ p $<0.01$ compared with data at -3 days.
\end{tabular}

In the present study, inoculated VRE were detected in all blood samples obtained from dead and dying mice. Simultaneously, E. coli was detected in almost all these mice, and the number of E. coli organisms was $\leqslant 10 \%$ of the number of VRE.

\section{Discussion}

Intestinal colonisation and overgrowth of orally inoculated microbes cannot occur unless the stability of the normal flora is upset by prior treatment with antimicrobial agents, use of purgatives, fasting or other factors. The normal intestinal flora resists colonisation by extraneous organisms. Previous studies have suggested that broad-spectrum antimicrobial agents such as the third-generation cephalosporins increase the risk of acquiring enterococcal-associated systemic infection by creating a selective milieu for enterococcal superinfection [13, 14, 19-21]. Moreover, the use of thirdgeneration cephalosporins has been used as a marker for enterococcal superinfection that can be fatal in some cases $[14,22]$. Furthermore, when the suitability of antimicrobial agents for prophylactic administration was investigated, the combination of kanamycin and metronidazole induced a good outcome except for the overgrowth of enterococci [23]. For this reason, these agents were selected to disturb the normal intestinal flora of mice in the present study.

Studies in gnotobiotic mice colonised only with anaerobic bacteria indirectly confirmed that anaerobic bacteria acted to prevent intestinal colonisation of orally administered bacterial pathogens [24]. Hentges et al. [25] indirectly indicated that other groups of intestinal bacteria might also function to prevent intestinal colonisation by potential pathogens. In the present study, a decrease of one $\log _{10}$ of anaerobic or aerobic bacteria by administration of metronidazole or kanamycin was not lethal in mice orally inoculated with VRE. Moreover, none of the mice died 6 days after oral inoculation of VRE, although at 14 days after final administration of the three agents, each at a dose of $200 \mathrm{mg} / \mathrm{kg}$, counts of viable total anaerobes and Bacteroides spp. were markedly less than in control mice with abundant growth of VRE. Stroud et al. [14] reported that the use of metronidazole, a therapeutic agent found to be a risk factor for increased morbidity and mortality, served as a potential marker for gastrointestinal tract inflammatory process; there was a positive correlation between metronidazole use and the development of $C$. difficile colitis in only 3 of 17 patients exposed to metronidazole. However, the remaining 14 patients in their study were diagnosed with some form of gastrointestinal tract inflammation (e.g., peritonitis, colitis, abdominal abscess, or cholecystitis) before the onset of enterococcal primary bloodstream infection [14]. These results indicate that other factor(s) (e.g., gastrointestinal tract inflammation) are probably involved in the translocation of intestinal microbes - with the exception of Bacteroides spp. Although intestinal anaerobic bacteria outnumber aerobic bacteria in the intestine by 100:1 or even 1000:1, anaerobes rarely translocate to extra-intestinal regions. For example, Hill [26] reported that of 74 indigenous strains of rabbit caecal anaerobes, none significantly adhered in vitro to the caecal epithelium. One hypothesis argues that anaerobes preferentially colonise the intestinal mucus layer and cannot attach to the epithelium. There is evidence that elimination of the mucus layer results not only in a noticeable increase in the populations of bacteria directly adherent to the enteric surface but also in the dissemination of normal intestinal bacteria into extra-intestinal tissues such as the liver and spleen [27]. The present study showed translocation of E. coli following changes in the normal intestinal flora induced by the administration of three drugs. This finding indirectly suggested that administration of three drugs might eliminate the mucus layer. Of particular interest was the fact that the appearance of VRE in the blood was intimately associated with translocation of the organism from the intestine to mesenteric lymph nodes. Colonisation of VRE in the intestine is a primary factor inducing systemic VRE bacteraemia.

The present data demonstrated that bacterial counts in the liver, spleen and MLN were higher and the ratio of organisms translocated into these tissues was higher 
than in mice not treated with cyclophosphamide. This finding strongly indicates that one of the risk factors enhancing systemic bacteraemia is neutropenia $[14,20,21]$. Furthermore, preliminary experiments showed that intraperitoneal administration of cyclophosphamide at a dose of $250 \mathrm{mg} / \mathrm{kg}$ resulted in severe leucopenia ( $\sim 900$ cells $/ \mathrm{ml})$ on day 4 after administration, although the number of leucocytes rapidly increased and recovered to $\sim 6000$ cells $/ \mathrm{ml}$ at day 7 after cyclophosphamide administration (data not shown). Following these changes, VRE organisms were administered orally on day 3 after cyclophosphamide treatment to enhance their translocation and migration to the bloodstream and subsequent growth in various tissues evading phagocytosis and killing.

Cytolytic (haemolytic) and protease (or gelatinase) activities, aggregation substance, lipoteichoic acid and hyaluronidase are known virulence factors for Ent. faecalis [27]. However, few reports have demonstrated similar virulence factors for Ent. faecium. Thus, the frequency of Ent. faecalis infection is higher than that caused by Ent. faecium among vancomycin-susceptible enterococcal bacteraemia [19]. In the present study, similar results were obtained with respect to pathogenicity between vancomycin-resistant Ent. faecalis and Ent. faecium. Of course, the frequency of bacteraemia with vancomycin-resistant Ent. faecium is higher than with vancomycin-resistant Ent. faecalis because the frequency of acquiring vancomycin resistance in the former is higher than in the latter $[28,29]$. When mice were killed the day after oral inoculation of VRE, many VRE-positive specimens contained $E$. coli, but VRE organisms outnumbered $E$. coli in those samples by $\geqslant 100: 1$. Only VRE are detected in blood samples of patients with bacteraemia and as these patients often receive antibacterial agents before admission [20-22], this clinical phenomenon might be explained by the presence of VRE and other co-existing organisms (mostly E. coli) that are susceptible to antibiotics given to these patients. Lipopolysaccharide is capable of inducing cytokines and chemokines that are known as key mediators and orchestrate the host immuno-inflammatory response to bacterial infection [30]. Taken together, these data show that $E$. coli may be closely associated with the induction of VRE bacteraemia. The role of $E$. coli in VRE bacteraemia is presently under investigation.

\section{References}

1. Murray BE. The life and times of the enterococcus. Clin Microbiol Rev 1990; 3: 46-65.

2. Gullberg RM, Homann SR, Phair JP. Enterococcal bacteremia: analysis of 75 episodes. Rev Infect Dis 1989; 11: 74-85.

3. Singh KV, Qin X, Winstock GM, Murray BE. Generation and testing of mutants of Enterococcus faecalis in a mouse peritonitis model. J Infect Dis 1998; 178: 1416-1420.

4. Woodford N, Johnson AP, Morrison D, Speller DCE. Current perspectives on glycopeptide resistance. Clin Microbiol Rev 1995; 8: $585-615$.
5. Uttley AHC, Collins CH, Naidoo J, George RC. Vancomycinresistant enterococci. Lancet 1988; 1: 57-58.

6. CDC. Nosocomial enterococci resistant to vancomycin United States, 1989-1993. MMWR Morb Mortal Wkly Rep 1993; 42: 597-599.

7. Perl TM. The threat of vancomycin resistance. Am J Med 1999; 106(5A): 26S-37S.

8. Endtz HP, van den Braak N, Verbrugh HA, van Belkum A. Vancomycin resistance: status quo and quo vadis. Eur $J$ Clin Microbiol Infect Dis 1999; 18: 683-690.

9. Moellering RC. Vancomycin-resistant enterococci. Clin Infect Dis 1998; 26: 1196-1199.

10. Kelly CP, LaMont JT. Clostridium difficile infection. Annu Rev Med 1998; 49: 375-390.

11. Reinke CM, Messick CR. Update on Clostridium difficileinduced colitis, part 2. Am J Hosp Pharm 1994; 51: 1892-1901.

12. Grayson ML, Eliopoulos GM, Wennersten $\mathrm{C}$ et al. Increasing resistance to $\beta$-lactam antibiotics among clinical isolates of Enterococcus faecium: a 22-year review at one institution. Antimicrob Agents Chemother 1991; 35: 2180-2184.

13. Jochimsen EM, Fish L, Manning K et al. Control of vancomycin-resistant enterococci at a community hospital: efficacy of patient and staff cohorting. Infect Control Hosp Epidemiol 1999; 20: 106-109.

14. Stroud L, Edwards J, Danzig L, Culver D, Graynes R. Risk factors for mortality associated with enterococcal blood stream infections. Infect Control Hosp Epidemiol 1996; 17: 576-580.

15. Wells CL, Jechorek RP, Erlandsen SL. Evidence for the translocation of Enterococcus faecalis across the mouse intestinal tract. $J$ Infect Dis 1990; 162: 82-90.

16. Wells CL, Jechorek RP, Maddaus MA, Simmons RL. Effects of clindamycin and metronidazole on the intestinal colonization and translocation of enterococci in mice. Antimicrob Agents Chemother 1988; 32: 1769-1775.

17. Sahm DF, Kissinger J, Gilmore MS et al. In vitro susceptibility studies of vancomycin-resistant Enterococcus faecalis. Antimicrob Agents Chemother 1989; 33: 1588-1591.

18. Miyazaki S, Ishii Y, Ohno A et al. In-vitro activities of 11 antibiotics against vancomycin-resistant enterococci isolated in Japan. J Antimicrob Chemother 1999; 44: 415-416.

19. Shaes DM, Levy J, Wolinsky E. Enterococcal bacteremia without endocarditis. Arch Intern Med 1981; 14: 578-581.

20. Edmond MB, Ober JF, Weinbaum DL et al. Vancomycinresistant Enterococcus faecium bacteremia: risk factors for infection. Clin Infect Dis 1995; 20: 1126-1133.

21. Lucas GM, Lechtzin N, Puryear DW, Yau LL, Flexner CW, Moore RD. Vancomycin-resistant and vancomycin-susceptible enterococcal bacteremia: comparison of clinical features and outcomes. Clin Infect Dis 1998; 26: 1127-1133.

22. Maki DG, Agger WA. Enterococcal bacteremia: clinical features, the risk of endocarditis and management. Medicine 1988; 67: 248-269.

23. Sumiyama Y, Nagao J, Nakamura S, Tsurumi K, Miyazaki S, Goto S. Prevention of postoperative infections in colon surgery. Hawaii Med J 1986; 45: 72-76.

24. van der Waaij D, Berghuis-de Vries JM, Lekkerkerk-van der Wees JEC. Colonization resistance of the digestive tract in conventional and antibiotic-treated mice. J Hyg 1971; 69: 405-411.

25. Hentges DJ, Stein AJ, Casey SW, Que JU. Protective role of intestinal flora against infection with Pseudomonas aeruginosa in mice: influence of antibiotics on colonization resistance. Infect Immun 1985; 47: 118-122.

26. Hill RH. Prevention of adhesion by indigenous bacteria to rabbit cecum epithelium by a barrier of microvesicles. Infect Immun 1985; 47: 540-543.

27. Jett BD, Huycke M, Gilmore MS. Virulence of enterococci. Clin Microbiol Rev 1994; 7: 462-478.

28. Clark NC, Cooksey RC, Hill BC, Swenson JM, Tenover FC. Characterization of glycopeptide-resistant enterococci from U.S. hospitals. Antimicrob Agents Chemother 1993; 37: 2311-2317.

29. Morris JG, Shay DK, Hebden JN et al. Enterococci resistant to multiple antimicrobial agents including vancomycin. Establishment of endemicity in a university medical center. Ann Intern Med 1995; 123: 250-259.

30. Wilson M, Seymour S, Henderson B. Bacterial perturbation of cytokine network. Infect Immun 1998; 66: 2401-2409. 